\title{
The Talented Young Sports Girl in the Senegalese Family: An Education in Anti-Eclosion
}

\author{
Souleymane Diallo \\ INSEPS, UCAD, Dakar, Sénégal \\ Email: leysougeoman@gmail.com,souleymane6.diallo@ucad.edu.sn
}

How to cite this paper: Diallo, S. (2022). The Talented Young Sports Girl in the Senegalese Family: An Education in Anti-Eclosion. Advances in Physical Education, 12, 29-41. https://doi.org/10.4236/ape.2022.121003

Received: October 21, 2021

Accepted: February 13, 2022

Published: February 16, 2022

Copyright $\odot 2022$ by author(s) and Scientific Research Publishing Inc. This work is licensed under the Creative Commons Attribution International License (CC BY 4.0).

http://creativecommons.org/licenses/by/4.0/

\begin{abstract}
Faced with the suspected or proven sporting talent of girls at the family level and at school and the socio-cultural conservatism of the domestic group even in the city (Dakar) and which enshrines the categorization of activities according to gender and exclusive of sport for young girls, it is permissible to wonder about the place that education gives to the emergence of girls' sporting talent in these two entities (family and school). Thus, the semi-directive interviews with six talented sportswomen playing at Dakar University Club (Basketball), at Gazelles team (football) and at INSEPS Handball team, with their mothers and with three of their former teachers made it possible to discover that girls talented in terms of sport have often been assimilated to boys, criticized by parents and encouraged by teachers. In fact, sport is perceived purely as a male activity that education for autonomy in the exercise of domestic and financial activities (empowerment) through the encouragement of schooling must participate in discouraging for girls. The obstinacy of teen schoolgirls in sports, who have become more distracted from studies, promotes conflicts with parents and mediations in favor of the expression of their talent.
\end{abstract}

\section{Keywords}

Family Culture, School, Girl, Sports Talent, Education, Anti-Hatching, High Level of Sport

\section{Introduction}

The innate sports talent hides very badly the strong dose of construction and supervision it undergoes before its emergence. In other words, the motor ex- 
pression of the player considered very well or excellent in a situation of "sports games" to speak like Parlebas (1986: p. 55) is the coordinated result of natural dispositions but also and above all of tireless supervision and work in favor of performance. In this debate, Schotte (2013) speaking about the performances in long-distance and middle-distance races of Kenyan and Moroccan athletes allows himself a discussion of the place of innateness in sports performance. $\mathrm{He}$ thus questions the essentialist and naturalistic theses of sports talent, particularly from an identification of the social logics at work in sports success. Good athletes are therefore produced from a tacit or formal collective work, socially and culturally founded. Ferréol \& Noreck (1993: p. 167) linked "the theme of sport to culture and lifestyles" as an element of the social norm to be internalized and transmitted through education. More precisely and as a "total social fact" (Mauss, 1966), sport constitutes, according to Ayachi (2015: p. 10), "a privileged object of study in that it crystallizes both beliefs and fantasies, practices and traditions, educational and societal issues". These latter are undoubtedly included in the works of Thomas (1975: p. 92) on the "five large classes of determinants of motor performance. These are physiological, morphological, psychological, psychomotor and sociological characteristics." In this way, these authors confirm the Durkheimian conception Durkheim (1922, p. 51) in which education is defined as" the action that the adult generation has taken under those who are immature to confront social life. It aims to motivate and develop in children in a certain number of physical, intellectual and moral states that regards him and the political society as a whole and the special environment in which he is particularly destined." Durkheim emphasizes first the physical aspects that integrate the five major classes described by Thomas and that incubate the rest of the personality. More recently, Salmela (2004) stated: “Apart from the essential elements of training and competition, and the least visible of the organization, we discovered the peripheral importance of the context, that is to say, not only the social context in which we are raised, but also the dimension of family support that promotes or slows down the development of exceptional sports performance." As a result, the successful expression of sporting talent, even at the highest level, is heavily smeared with basic education and supervision in the medium and long term. It is primarily framed by the social environment of belonging and more particularly by the family which, according to Diallo (2005: p. 22), ensures "the transmission of cultural values, hence its characteristic as a socio-educational environment by excellency." In "coaching and parenting", Salmela (2017) highlights more precisely, the important roles of parents in promoting sports excellence. It should be noted, however, that the family, the first instance of production and tacit or formal detection of children's sporting talent, has evolved considerably in its structure. Thus, from the point of view of the sociology of the family, there are several typologies in terms of the organization of the domestic group that refer to specific socio-economic contexts. There are generally three historical periods in which three dominant types of families cor- 
respond. According to Barriere-Maurisson (1984: p. 253): "it is respectively the patriarchal family (before the industrial era), the conjugal family with the development of work and wage labor, and the family with two contributors because of the development of women's work." This latter is mostly observed in a city like Dakar where the Guardians of Cultural Orthodoxy (Customary Chiefs) and Religious (Imam and Preachers) always militate in favor of unity, presence and do not exist to remind the city dwellers of the realities and the values that exert the distribution of roles and tasks according to sex. Recalling from the point of view of purely high-level sports, de Coubertin (1894) was one of the first defenders for the exclusion of women from high competition after the interpellation of the prisoner Alia Milat who asked him to include feminine tests at Winter Olympics. He said: "The real Olympic hero in my eyes is the individual adult male. The Olympic Games must be reserved for men, the role of women should be above all to crown the winners." As if to reinforce it, Goffman (2002) noted that in sport, "Men dramatize their virility by displaying a demanding and violent character, while women stage their femininity by being gentle and soothing. These stereotypical gender behaviors constitute 'gender parades'." In the same logic, Senegalese culture, in particular, seems to exclude from its framing the sport of girls even if they have talent. Indeed, characterizing social representations of women's sport, Ndiaye (2011) noted: “Girls engaged in training and sports competitions are the subject of sharp criticism from their parents who keep reminding them that they are girls and that their value can only be expressed in relation to the good management of the home and submission to a husband (...). Women's sport poses a problem relating to the influence of Western culture that can lead to a transformation of local fundamental values and against which family resistance is still evident even in the city." As a result, the family education of girls in general and of those with proven sporting talents, in particular, is still almost dependent on this limiting cultural framework and therefore a source of inhibition and discouragement of the skills shown by girls in terms of sports practice even if they are "disciplines with a feminine connotation" (Laberge, 2004) such as basketball, volleyball, handball, etc. But in the face of these claims, which are certainly based on validated studies and which mainly back about a decade, or even more, in the face of rapid social change driven by the diversity of communication canons, a source of polishing of extremist attitudes, it is logical, even imperative to ask in 2020, the following research question: Does the Senegalese family, as a basic unit of society and today strongly modernized and supported by the school especially in the city (Dakar), in its transmission of the values and rules of social life to the children and girls in particular that it is responsible for educating, does it give a place to the hatching and/or promotion of the sporting talent of its gifted daughters? The aim of this study is to understand the different characteristics of the family and school education of talented young sportswomen in a city like Dakar and its sources of obstacle to the development and blossoming of their talents. That is the reason 
why, the text, in accordance with the requirements of the scientific approach, highlights the methodology, the results of the study focused, on the one hand, the valorization of the exclusive female physical beauty of sport, and then, on the other hand, the family educational actions against hatching, the expression of the sporting talent of girls and finally the conflicts between the players and their parents. In the last instance, the results were the subject of a discussion that allowed them to be interpreted and to increase the contribution of the study compared to previous research.

\section{Methodology}

The study was conducted in Dakar, the Senegalese capital and in 2 large Senegalese capital clubs known for their consistency in the elite in female sports. These are DUC (Dakar University Club) for basketball (16 times Senegalese champions) and Grand Yoff (Dakar) Sirens in football, 13 times Senegalese champions. The diversification of sports responds to an analysis of parents' reactions according to the sports practiced by the girls and in relation to the family cultural norms. These different teams have the peculiarity of being distinguished in their respective disciplines and in matters of female sport.

In these teams and to answer our research question, we have mainly used the qualitative methods as techniques to collect semi-directives with the 6 moms of the best players out of 3 in each team. These ladies were born or settled in Dakar wherewith their husbands, founded a home and educated their offspring. They live precisely in Grand Yoff, Medina, Grand Dakar or Pikine. These talented players are also asked about the family educational constraints caused by their need to express their sporting talents. These talented girls in sports were chosen according to three criteria:

- They totalize more than ten starts in the A team;

- Their talent is essential according to their coaches and some supporters;

- They live in our field of study and in their birth families.

With this same technique (semi-directive interview), exchanges took place with two (2) schoolmasters and one (1) physical education and sports teacher who are on service and who had taught them.

Let's remember that the tools, i.e. the Interview Guides have been tested and corrected twice with students and players of the National Higher Institute of Popular Education and Sport titular in the Basketball team of the same institution and evolving in the second division

The analysis and comparison of the data collected from our various respondents' thanks to this collection technique and those obtained by documentary research made it possible to discover the limiting family educational practices of girls' sports talent in Dakar as well as the important role played by the school.

\section{Results}

From birth to 18 years of age, children are usually supervised and educated in 
two social institutions, namely the family and the school. Depending on gender, social status and roles are valued to the detriment of others such as sport for the girl. This is why, in this study, the educational aims for talented sportswomen are first apprehended in these two entities. Then, the discouraging actions of the sports talent of the targeted are highlighted. Finally, in college, the need to affirm the gift of sport faces parental reluctance.

\subsection{The Sporting Talent of Young Girls: From the Family and the Primary School}

Family education, even in the city, is always related to a culture that for the case of talented sports girls is indicative of a blockage while schools offer themselves as an environment of discovery and supervision of the schoolgirls in question.

\subsubsection{The Family, Cultural Instance of Blocking Suspicion of Sporting Dispositions of Girls}

Generally speaking, sporting talent represents all the qualities and skills necessary to achieve great performances. In this regard, Monpetit \& Cazorla (1990) define it as "the quality presented by an individual offering a higher level of physiological attributes and motor skills than the average level of individuals of his age." As if to complete Cazora (2004: p. 16) insists on these qualities of the talented athlete who "allow to predict high probabilities of achieving, in the more or less long term, a high performance in a given field (...) if the young person has the will to do so and if he meets the most favorable conditions for his sporting development.." And since it shows itself very early, "before 10 years for many sports" (FFA) ${ }^{1}$, the conditions of his discovery begin in the family before confirming to school in the different competitions between classmates. In a city like Dakar and especially for the girls, it is manifested by anti-conformist youth attitudes and behaviors in relation to the social classification of physical, playful, ordinary activities with the fratri. The passions and occupations of the talented sports girl in becoming are critically acclaimed by the other brothers and sisters who complained to mothers. These latter begin to be more attentive by reports of the actions of their daughters according to them "any qualified behavior of masculine and incarnate by the daughters is synonymous with failure in their education. Our responsibility is ours and we are often criticized by our people." The masculine behavior is according to their intention "participate in the games of boys and compete with them, follow the sports TV shows instead of the movies and series, play football, play with the boys, etc." By qualifying the feminine beauty that must be built in the girl, the mothers of these sports champions highlight "the body softness, the feminine physical form, the cuisine and cleanliness, the nonchalant expression and gait, etc. because the woman's body must not be muscular, robust, rough, etc." By expressing themselves in this way, mothers summon their cultural landmarks characteristic of the woman of yesteryear, thus giving reason to Perrot (1984), for whom "the history of women was ${ }^{1}$ FFA stands for French Athletics Federation. 
first and foremost a history of their bodies (...), sexual bodies, maternity, work (...), denied, masked, repressed", " even if they admit to advocating for the non-dependence of the daughters of their future husbands by defending the idea that "I want my daughter to go to school and get a good situation and a good understanding husband. And it is not a sport that can give it to him. Thus, sport and a bright socio-professional future are therefore not compatible in their logic.

In fact, these girls who stand out in high-level sport in Senegal have very vague memories of this period but mostly recognize that their mothers were not tender with them every time they played with boys or engaged in so-called male activities. This is why, particularly because of the narrowness of the premises (houses) and especially the parental injunctions limiting their playful preferences, these talented sportswomen in miniature were in a hurry to go to school where, in their own words, "we filled all the gaps in terms of sports expression and competed with the boys in Physical Education (PE) and in the playground."

\subsubsection{The School or the Place to Discover the Sporting Talent of Girls}

The school was another family, the family of youth, sports games, exchanges; a place where children of almost the same age are grouped together in what is commonly referred to as the class. The latter has the particularity of grouping boys and girls in the same enclosure and around an adult (schoolmaster) obligated promoter of equal opportunities (Law 91-22), equity and developer of physical and intellectual capacities. "Seats were not allocated on a gender-sensitive basis. Sweep groups and PSE teams were mixed. Rivalry with the boys was a source of motivation. The masters carried out constant rebalancing because we were decisive (...). Our teachers had probably discovered what we had more than others in the field of EPS."

In other, the distinction of sports practiced for specialization in football, basketball in handball, etc. did not exist. "Only the program dictated to the teacher what he had to do to the students. Therefore, physical aptitude, velocity, resistance, intelligence in the practice of sports games, etc. were the barometers for the detection of talents," the teachers argue. As a result, telltale signs of future talent were quickly detected by teachers and other students who measured themselves therapy in the playgrounds. However, some talented girls were afraid that their sports performance would be reported to their parents. If necessary, for the majority of them, these schoolgirls were the subject of harsh criticism and even "whip correction and words reminding us of our femininity that must determine our activities and actions as well as the reason why we were brought to school: to be excellent in so-called cognitive disciplines such as mathematics, French, scientific and technological initiation, etc. and become respectable personalities."

Definitely, despite the installation in the city, the families of the girls who demonstrate the talent in sports matters, remain conservators of the traditional educational contexts. Because of their playful and entertaining passions, these girls are assimilated into boys and severely criticized by the fraternity and parents. This is the educational failure of mothers and this manifesting trend is de- 
veloping. This is why these girls who free themselves at school and are well appreciated by the masters in PE classes are afraid that their sports activities and performances will be brought home. This exposes them to criticism and corrections.

\subsection{Feminine Sports Talent Encouraging Family Educational Activities}

There are many discouraging family educational activities. They are tailor-made and/or informally according to the objective assigned to the education of the girl in general, namely virtue in the sense of Mungala (1982: p. 2) and which fits well "African values and social integration in which the embodiment of femininity through culturally accepted activities as feminine" and the promotion of academic success as factors of economic and financial empowerment, are positives.

\subsubsection{Feminine Sport: Clichés of Assimilation to Men and Liberation}

The most shared social representation of sport is exclusive to women. There is no room. This is why girls seeking to find a future there have encountered strong to moderate parental resistance. Here, two steps can be clearly distinguished. The first is the period from 6 to 12 years corresponding to the age of attendance at elementary school where parental supervision, especially of the mother, is strongly marked. It is punctuated by hours of presence of the girl at home and others during which she must imperatively be at school. According to some girls showing a proven sporting talent "between the descent and the house, time is running out (...) From morning to night, our time at home is punctuated by household chores." Indeed, for some, the schedule was as follows. get up early in the morning and pray, assist mom in the preparation of breakfast (go buy bread, wash cups, serve coffee to the boys, etc.), wash the bowls and wait for mom to return from the market to assist her in the kitchen and all other tasks related to secondary household activities. The time that had to be used to go play basketball, handball, football, etc. is redirected towards purely "feminizing" guidelines. Nothing in the educational discourse of mothers encouraged the practice of sports. Activities related to sports games were severely criticized. The chorus was the same "it looks like a boy". This social representation of the daughter internalized by mothers constitutes clichés that prevent the acceptance of sports and reinforces the pessimism of mothers with regard to the future of their daughters. This position lays bare the internalized and prevailing cultural realities that favor appreciations according to the tacit social division of activities in relation to age and gender. In the opinion of Pociello (1981): "The place that one occupies in society determines the type of relationship that one maintains with one's body and greatly determines the uses, especially sports, that one makes of it." More precisely and as if it reinforced this position, Louveau (2004: p. 169) expressing himself on the assessments of women's sport emanating from the collective conscience, wrote: "Versant given as positive (the sportswoman shown smiling, not in the effort and its substrate, sweat, the one whose forms, smile or grace, in short femininity are praised) and negative side (the so-called too muscular, an- 
gular sportswoman, in short described as masculine) are two sides of the same expectation weighing on sportswomen and that the media reveal. It is always the same woman who is expected, ideal and canon, seductive to whom is assigned above all a decorative function and sexual object."

The second period corresponds to studies at the college. The jobs of the irregular times of the girls begin to escape to the mothers. They become more audacious in the exercise of their passion: the sport. Due to the rarity of land in the neighborhoods, the play areas of the colleges become the privileged places of expression of sporting talent and "measure to the other girls and boys there was the first deficit in EPS. The second was to win our class in the interclass matches in handball and basketball." The sports distinction begins to install. The options for women's sports (handball, basketball) have become even stronger, manifesting themselves as a sort of classification dictated by sex (....) And explained by Mennesson (2005) in these terms: "Even when a girl refuses to enter a sport' for girls" and submits to the necessary learning to internalize dispositions adjusted to the practice of a "manly" sport, she hardly obtains the recognition of male practitioners who reproach her either for her lack of femininity or her pseudo-masculinity (...). "The escape tricks of critics and missions in guarding in families become more elaborate. The girls dissimulate the sports uniforms in the bags or, with the convenience of classmates find the means to get out of the house the sports equipment. Some of them to which time jobs are advertised by mothers find the means to modify in order to manage free time away from home and to adhere to sport and school. The doubts of some mothers are manifested by the proposals as "morning school, evening school, all days..." and "to this rhythm, your risks of never staying long at your future husband. A good woman, we find her at home and on her mother's cottages. We can no longer distinguish between boys because of the way they behave, how they behave, their tastes... You don't do anything feminine. Looks like a boy..." These slogans remain and are still held in the heads of the girls whom they often recall in their speeches.

\subsubsection{The Prioritization of Managerial Autonomy and School Success to the Detriment of Sporting Success}

All education is oriented towards an ideal judging objective. In fact, this is the future of young people who are into gaming. Two essential factors are generally combined: cultural conformism and the autonomy of the product, the educated. Two essential factors are generally combined: cultural conformism and the autonomy of the product, the educated. Sporty girls are no exception to this rule. Sporty girls are no exception to this rule. In the case of autonomy, some mothers highlight the ability to manage a household. In the case of autonomy, some mothers highlight the ability to manage a household. If necessary, they focus on several know-how (know how to cook, know how to clean, be welcoming and hospitable, know how to take care of a spouse according to the Senegalese culture that relates to submission, etc.) In the declined list, sport does not appear even if skills in this direction are manifested by girls. Obviously, it is for these la- 
dies a question of a household autonomy, the know-how. They work it by favoring the pragmatic approach: learning by doing to speak like (Dewey, 1990) and do not even want to hear about the girl-sport couple. "It's incompatible or even a huge waste of time."

In addition, the schooling of these sports girls is favored on the one hand, by the attachment of parents to school because they have attended in their vast majority of elementary to intermediate educational institutions and university for those who have gone further and on the other hand by public policies of access to schooling (PDEF, Education for all, SCOFI, PACKAGE) carried by a discourse on gender, parity, equality, equity, etc. Talented sportswomen had attended private and/or public schools a few years earlier. The schooling of these sports girls has been strictly monitored by parents. The objective pursued and manifested in the discourse of mothers is economic and financial autonomy, that is to say "empowerment" in the sense of Kabeer (2002: p. 256). That is why, at home, the emphasis on learning lessons, the recruitment of a coach (for 4 girls), the very positive appreciation of good grades and averages as well as the best academic ranks are frequent and promote the joy and pride of parents. The awards of the good rankings at the end of the compositions attest to the willingness of the parents to push these girls to academic success. Similarly, bad grades are severely criticized and their perpetrators punished.

Overall, women's sport is poorly perceived at the family level. It is assimilated to an unnatural male activity for girls who must be and remain gentle and submissive, objectives for the achievement of which they are the subject of a strict education. Better still, the discouraging educational activities of the expression of girls' sporting talent are inherent in the empowerment of girls in household management, the mastery of culturally valued domestic activities and the monitoring of girls' schooling perceived as a source of economic and financial independence (empowerment) in the future.

\subsection{From the Need for Sports Affirmation to Parental Reticence: The Conflicting Players/Parents}

From the $6^{\text {th }}$ to the $3^{\text {rd }}$, girls are usually in adolescence. The mistrust of certain parental directives is in order. The need to have greater freedom because we consider ourselves great and responsible is obvious. These talented girls in sports feel the need to highlight themselves through body refinement and sport, their strength. The latter is a source of success and envy because after the first interclass meetings, in UASSU or FOSCO where they make the difference by winning their classes and schools. The attention of teachers and boys is more oriented towards them with different objectives. The former, who are especially their PE teachers, show the need to encourage and protect them so that the potential sporting talent can one day blossom. They often offer them specific training, do not hesitate to put them in contact with basketball, football or handball clubs and suggest that they continue their studies at INSEPS after the baccalaureate. The latter want at all costs to approach them "to make a buzz". Both situations 
reach families who begin to notice unusual absences of girls from the house. The deductions of mothers punctuated with fury are then made "she wants to show that she has become great which is why she comes home when she wants and often after the twilight prayer. She is only 13,14 or 15 years old. If she wants to indulge in libertinism, she will find me on her way (...) I will show him that I am his mother.". Faced with this situation, girls are dying to provide elements of explanation even if they are not listened to and feel the need to justify by going to find witnesses who are their classmates. Some of them are convinced that their determination is never eroded by parental injunctions. In their words, "the strategic mistrust of parental authority" was to follow. The diplomacy of paternal aunts and uncles is solicited because "only they can twist the arm of moms and dads." The others are open to teachers and principals who sometimes make the trip to explain the absences of girls from the houses during certain hours and ask permission for them while assuring that there will be no libertinism and, as educators, they will strictly watch over it.

On closer view, families are afraid of the excesses in terms of sexuality that "sport and adolescence combined can generate". They are aware that at this age distraction takes precedence over the concentration needed to study. "The pace of learning at home decreases because they come back very tired of training and matches that we are finally forced to accept with the guarantees of supervision of PE teachers and other officials." Their gift for sport highlights them every time they return from a performance. They are not aware of their vulnerability at this age of adolescence reported under the term "risky behaviors" by Archimi \& Jordan (2014) where they themselves, capriciously, can cultivate the rapprochement with boys. Moreover, it has been proven that in adolescence, physiological transformations are accompanied by behavioral disorders pushing to revolt even against parental decisions because of "the autonomy sought by young people and even torn (...) (Lévy, 2019: p. 2).” The need to assert one's personality is real and the fact of having a boyfriend plays an important role hence the great conflicts with the parents which sometimes lead to the exchange of sour words and tears. With this situation, mothers have, at one point, wondered about the educational future of their talented sports daughters who, however, in their overwhelming majority (5/6) have had the baccalaureate and continue their studies at the university. Those who are at INSEPS (2/6) are convinced that employment as a PE teacher is guaranteed provided they succeed to the final exam $\left(\right.$ CAPEPS $\left.^{2}\right)$.

In short, with the affirmation of sports talent in college, parental anxiety increases because of the adolescence of girls and sport. These two elements are a source of distraction that disorients the players of the studies, promotes conflicts and mediations in favor of the practice of sport.

\section{Discussion of Results}

In the opinion of Quivy \& Van Campenhondt (1990: p. 32): "It is unlikely that ${ }^{2}$ CAPEPS stands for Certificate of Aptitude for Teaching Physical and Sports Education. 
the subject matter has never been addressed by anyone else before at least in part or indirectly. All research work is part of a continuum and can be located in or in relation to currents of thought that precede or influence it". Several previous scientific studies have focused on the sociology of sport in general and particularly on sports inequalities between culturally constructed girls and boys. Thus, the delicacy of making its way in this theme treated by several authors from different angles raises the problem of its specification based on the pairs of words family-culture, sport-girl, city-education.

In addition, the study is diachronic, therefore based on memories of significant educational actions and oriented towards the discouragement of women's sport. Does the choice of sports girls with the majority of the baccalaureate at university make it possible to comprehensively understand the family successes in terms of discouragement of the expression of talent of young sports girls? How many girls couldn't resist? The extension of the field of study to other countries different from Dakar on the cultural, religious, economic, etc. levels and the taking into account of certain innovative positions that are quite rare in the study confirming the Charters of Sport of UNESCO (1978: art. 1st) and Senegal (Law 84-59) and according to which, in essence, "Sport is a fundamental right for all, without discrimination and must be promoted by all governmental, sporting, school and educational institutions" could change the results in the direction of their relativization. Indeed, the convergence of the data emanating from the answers obtained and analyzed certainly makes it possible, in this specific case, to make interesting analyses, but the confrontation of contradictory positions that has been lacking in this research would help more to reinforce or weaken the results. Moreover, Jurdant (1998: p. 279) rightly stated: "that it is necessary to take into account the divergences, to multiply ever more the elements of a situation in order to create the conditions for a positive controversy on the validity of the results."

Moreover, the tones used today by mothers to answer questions do not seem to reflect the firmness of yesteryear described by sportswomen. The hope of seeing their daughters succeed in studies and make a name for themselves in basketball, handball and football, etc. is further consolidated. There is almost no more surveillance. Does this situation attest to a change in mentality, resignation, trust or accountability with the maturity of girls? The study ignores these questions, the answers to which could make some claims questionable because of the culture's resilience to the changes observed.

\section{Conclusion}

The decades-long settlement of the families of talented sports girls in the city has not greatly influenced perceptions of the relationship between sport and girls. The cultural and educational conservatism of female children characteristic of the Senegalese tradition, in particular, classifies and values sexual activities whose transgression exposes the perpetrators to criticism and punishment Sport 
is one of the concerns almost excluded from the field of activity of girls under penalty of assimilation to boys by siblings and mothers who qualify these attitudes of their talented offspring as an educational failure if the observation evolves favorably towards the emergence of talents. Thus, the school is the only framework for expressing their physical abilities that are squarely above average compared to the pupils of their age that they use in recess or in physical education and sports lessons while not having to report performance at home under penalty of corrections. The clichés of masculinization of sport at the family level refer in turn to classifications of characteristics (softness, submission, refinement, etc.) and activities considered feminine such as those adopted by mothers for the education of girls, namely: the household management of the home, the mastery of domestic activities, etc. The objective is above all education for autonomy, which takes on the appearance of promoting "empowerment", which translates into a goal of economic and financial independence and which justifies sending girls to school. But with age, that is to say in college, adolescence and sports passion combine to promote parental anxiety because of distraction, disorientation more and more studies, conflicts with parents and mediations in favor of sports practice. This is why awareness-raising actions among parents are essential to promote the rapid expression of these talents. Therefore, it seems essential to us, to integrate into the formal education system specialization, from an early age, in the innate field of predilection of children.

\section{Conflicts of Interest}

The authors declare no conflicts of interest regarding the publication of this paper.

\section{References}

Archimi, A., \& Jordan, M. D. (2014). Vulnerability to Risky Behavior in Adolescence: Definition, Operationalization and Description of the Main Correlates among 11-15 Year Olds in Switzerland. Research Report No. 67, University of Lausanne.

Ayachi, S. (2015). Women in Sports with a Masculine Connotation: Identity Strategies of Tunisian High-Level Athletes. Doctoral Thesis, University of Franche-Comté.

Barriere-Maurisson, M. A. (1984). Treatise on the Sociology of Work. Presses Universitaires de France.

Cazora, G. (2004). La détection des jeunes talents-definitions, limites, tendances et exemple. Mémoire de Master soutenu à l'Université Victor Segalen Bordeaux II.

De Coubertin, P. (1894). Discours pour la rénovation des J.O. Sorbonne.

Dewey, J. (1990). Démocratie et Education. Editions Armand Colin.

Diallo, S. (2005). Familles et usages de la télévision à la Médina: Le cas des jeunes de Thieurigne. Mémoire de DEA, Département de sociologie, UCAD.

Durkheim, É. (1922). Éducation et sociologie. PUF Quadrige.

Ferréol, G., \& Noreck, J. P. (1993). Introduction à la sociologie. Editions Armand Colin.

Goffman, E. (2002). L'Arrangement entre les sexes. Éditions La dispute.

Jurdant, B. (1998). Impostures scientifiques. La découverte/Alliages. 
Kabeer, N. (2002). Réflexion sur la mesure de l'empowerment des femmes. Traduit de l'anglais par Emmanuelle Chauvet (pp. 253-274). Chahiers genre et développement.

Laberge, S. (2004). Les rapports sociaux de sexe dans le domaine du sport: Perspectives féministes marquantes des trois dernières décennies. Revue Recherches Féministes, 17, 9-38. https://doi.org/10.7202/009295ar

Lévy, S. (2019). Troubles du comportement chez les adolescents. Harward Médical School.

Louveau, C. (2004). Sexuation du travail sportif et construction sociale de la féminité. Cahiers du Genre, N³6, 163-183.

Mauss, M. (1966). Sociologie et anthropologie. Paris: Presses Universitaires de France.

Mennesson, C. (2005). Etre une femme dans le monde des hommes. Socialisation sportive et construction du genre. Paris: L'Harmattan.

Monpetit, R., \& Cazorla, G. (1982). La détection du talent en notation. La Revue de l'entraîneur, $\mathrm{N}^{\circ} 5,26-37$.

Mungala, A. S. (1982). L'éducation traditionnelle en Afrique et ses valeurs fondamentales. Ethiopiques: Revue Socialiste de Culture Négro-Africaine, $\mathrm{N}^{\circ} 29,51-71$.

Ndiaye, M. (2011). Les causes de l'arrêt de la compétition sportive chez la femme sénégalaise. Mémoire de maîtrise és STAPS, INSEPS/UCAD.

Parlebas, P. (1986). Eléments de sociologie du sport. Paris: Éditions Presses Universitaires de France.

Perrot, M. (1984). Une histoire des femmes est-elle possible. Marseille, Paris: Rivages, 228 p.

Pociello, C. (1981). La force, l'énergie, la grâce et les reflexes. In C. Pociello (Ed.), Sport et Société (pp. 171-237). Éditions Vigot.

Quivy, R., \& Van Campenhondt, L. (2017). Manuel de recherche en sciences sociales (5th ed.). Editions Dunod.

Salmela, J. H. (2004). Familles et performance expert. Revue STAPS, N64, 9-12.

Salmela, J. H. (2017). Coaching and Parenting. In M. Jemni (Ed.), The Science of Gymnastics. Routledge. https://doi.org/10.4324/9781315203805-14

Schotte, M. (2013). La construction du "talent"-Sociologie de la domination des coureurs marocains. Raisons d'agir.

Thomas, R. (1975). La réussite sportive. Presses Universitaires de France.

UNESCO (1978). International Charter of Physical Education and Sport. UNESCO. 